\title{
रागदारी संगीत का स्तम्भ रागांग
}

\section{Dr. Aparna Shukla}

Assistant Professor, Shri. Agrasen Kanys P.G. College, Varanasi

\section{ABSTRACT}

In Indian classical music, 'Ragang' has been used since ancient times. Matang Muni first mentioned Ragang under the Trived indigenous ragana (ragang, bhashang, kriang). After that Sharangdev followed Matang Muni. At present, Ragang has a special significance in North Indian classical music. Although the Thaat-Raga system of raga classification is propagated but the Thaat system is propagated only on the scriptural elements of the ragas, but those who emulate the Thaat method also acknowledge the importance of Ragang. It also gave ample space to Ragang in that arrangement. At present, Pt. Narayan Moreshwar Khare is credited for arranging it as a method and bringing it to use. Ragang Raga means that the vocal accompaniment occupies a specific place in a raga and by incorporating it in any other raga. It is recognized as a part of that raga by the name of the same organ or type. The ragas with this particular part are named Ragang.

Keywords

Raagdari Sangeet, Ragang, North Indian Classical Music

\section{सार संक्षेपिका}

भारतीय शास्त्रीय संगीत में 'रागांग' पुरातन समय से ही प्रयोगार्थ है। सर्वप्रथम मतंग मुनि ने त्रिविध देशी रागों (रागांग, भाषांग, क्रियांग) के अन्तर्गत रागांग उल्लेखित किया। तत्पश्चात शारंगदेव ने भी मतंग मुनि का ही अनुकरण किया। वर्तमान समय में उत्तर भारतीय शास्त्रीय संगीत में रागांग की अपनी एक विशेष महत्ता है। यद्यपि राग वर्गीकरण की थाट-राग प्रणाली ही प्रचारित है परन्तु थाट पद्धति केवल रागों के शास्त्रगत तत्वों पर ही प्रचारित है परन्तु थाट पद्धति को अनुकरण करने वाले भी रागांग महत्व को स्वीकारते हैं, पं. भातखंडे जी ने रागांग तत्व की महत्ता को स्वीकारा तथापि अपनी थाट व्यवस्था में रागांग को पर्याप्त स्थान भी दिया। वर्तमान समय में इसे एक पद्धति के रूप में व्यवस्थित कर प्रयोगार्थ में लाने का श्रेय पं. नारायण मोरेश्वर खरे को दिया जाता है। रागांग राग अर्थात् जो स्वर संगति किसी राग में अपना विशिष्ट स्थान बना लेती है और अन्य किसी भी राग में समाविष्ट करने से उस राग का अंग बनकर उसी अंग या प्रकार के नाम से पहचानी जाती है। इस अमुक अंग वाले रागों को रागांग नाम से अभिहित करते हैं।

बीज शब्द

रागदारी संगीत, रागांग, उत्तर भारतीय शास्त्रीय संगीत

\section{भमिका}

भारतीय शास्त्रीय संगीत में 'रागांग' कोई नवीन कल्पना नहीं है। संगीत सम्बन्धी पुराग्रन्थों में भी रागांग शब्द व्यवहृत है। राग उद्भव के साथ ही रागांग की ऐतिहासिकता भी जुड़ी हुई है। रागांग की इसी ऐतिहासिकता के सन्दर्भ में पं. रातंजनकर जी ने कहा है कि भरतकालीन जातियां जिन्हें उन्होनें राग की जननी माना है, अपनी अंगभेद विस्तारमूलक प्रवृत्ति के कारण रागांग परम्परा की सर्वप्रथम उद्भाविकाएँ कही जा सकती है, जातियों से रागों की उत्पत्ति, जाति के अंग-प्रत्यंग, स्वर संगतियां अथवा मुरक्कीवाद लेकर होती थी। 1 यह स्पष्ट तो हो रहा है रातंजनकर जी के कथनानुरूप कि प्राचीन जातियों से रागों की उत्पत्ति का आधार उनकी विशिष्ट-स्वर संगति अर्थात अंग विशेष को ही माना। मतंग मुनिकृत बृहदेशी ग्रन्थ में सर्वप्रथम 'रागांग' शब्द का उल्लेख प्राप्त है। मतंग मुनि ने त्रिविधि देशी रागों (रागांग, भाषांग, क्रियांग) के अन्तर्गत रागांग का उल्लेख इस प्रकार किया है - 
उक्तानां ग्रामरागाणां छायामात्रं भजन्ति हि।

गीतज्ञै: कथिता: सर्वे रागांगास्तेत हेतुना।।2

अर्थात् ग्राम-रागों की छाया से युक्त सभी रागों को, गीत को जानने वाले व्यक्तियों ने 'रागांग' कहा है। दृष्टव्य यह है कि मतंग मुनि ने प्रचलित रागों को ग्राम राग व देशी रागों में विभाजित किया और उन्ही देशी रागों के अन्तर्गत रागांग का उल्लेख किया है। पं० शारंगदेव ने भी मतंग मुनि के मत का ही पालन किया है किन्तु उन्होंने देशी रागों के अन्तर्गत रागांग भाषांग क्रियांग के साथ-साथ उपांग को भी जोड़ा है-

\section{अथ रागांगभाषांगक्रियांगोपांगनिर्णयम् । \\ केषाजिचन्मतमाश्रित्य कुरूते सोढलात्मजः $11^{3}$}

उक्त श्लोक के भावार्थ में ग्रन्थकार ने कहा कि रागांग, भाषांग, क्रियांग, उपांग ये चार प्रकार देशी रागों के माने हैं। संगीत रत्नाकर में ग्रन्थकार ने पूर्व प्रसिद्ध एवं अधुना प्रसिद्ध रागांगो को इस प्रकार बताया है-

पूर्व प्रसिद्ध रागांग

शंकराभरणो घंटारवो हंसकदीपकौ ।

रीतिः कर्णाटिका लाटी पाज्चालीति बभाविरे । ${ }^{4}$

अर्थात् - शंकराभरण, घटारव, हंसक, दीपक, रीति, कर्णाटी, लाटी, पंचाली ये आठ रागांग पूर्व प्रसिद्ध हैं।

आधुनिक प्रसिद्ध

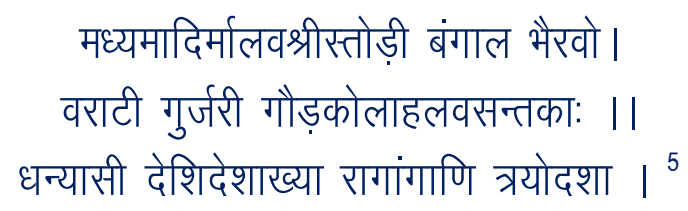

अर्थात् - मध्यमादि, मालवश्री, तोड़ी, बंगाल, भैरव, वराटी, गुर्जरी, गोड़, कोलाहल, बसन्त, धन्यासी, देशी और देशाख्या ये तेरह रागांग हैं। इस प्रकार शारंगदेव जी ने 8 पूर्व प्रसिद्ध रागांग और 13 अधुना प्रसिद्ध रागांग, कुल इक्कीस रागांगो का उल्लेख किया है।

"रागच्छायानुकारित्वात् रागागानि विद्रुर्धा:":

अर्थात् - राग की छाया का अनुकारी होने के कारण इसे रागांग कहा गया है। पार्श्वदेव जी ने अपने ग्रन्थ में बारह सम्पूर्ण, चार षाडव तथा चार औडव रागांग, इस प्रकार कुल बीस रागांग कहे हैं। 
उमापति कृत ग्रन्थ 'औमापतम् में ग्रन्थकार ने बारहवें अध्याय में रागांग, भाषांग, क्रियांग उपांग आदि का उल्लेख किया है, उमापति जी ने बीस रागांग बताये हैं। नारदकृत 'संगीत मकरन्द' में भी रागांग का वर्णन प्राप्त होता है, ग्रन्थकार ने रागांग की परिभाषा नहीं दी परन्तु तेरह रागांग बनाये है। ${ }^{8}$ आचार्य सुधाकलश रचित 'संगीतोपनिषत्सारोद्धार' में तृतीय अध्याय में रागांगो का वर्णन किया है। ग्रन्थकार ने तीसरे अध्याय में रागांगों का वर्णन किया है इन्होने चार रागांग बताऐ हैं देवशाख, मालवश्री, धनाश्री एवं दीपक ${ }^{9}$

अधुना समय मे उत्तर भारतीय संगीत जगत में रागांग की अपनी एक विशेष महत्ता है। हालांकि वर्तमान समय में राग वर्गीकरण के अन्तर्गत थाट पद्धति प्रचार में है किन्तु ये पद्धति मात्र शास्त्रगत बनकर रह गई है परन्तु प्रचारतः क्रियात्मक रूप से प्रायः रागांग के आधार पर ही राग अवगत कराये जाते हैं। पं. भातखंडे जी ने भी रागांग तत्व की महत्ता को स्वीकार किया है तथापि अपनी थाट व्यवस्था में रागांग को पर्याप्त स्थान भी दिया है। यद्यपि वर्तमान में रागांग पद्धति के जनक कहे जाने वाले पं. नारायण मोरेश्वर खरे का नाम रागांग पद्धति के प्रचार-प्रसार में विशेष रूप से उल्लेखनीय है। मोरेश्वर जी के शब्दों में "किसी भी राग का मुख्य आधार एक प्रकार के विशिष्ट स्वरसन्दर्भ पर स्थित होता है। बहुत सी स्वररचनायें स्वतंत्र होती हैं, जिनमें से विशेष प्रकार के भाव अथवा रस का आविर्भाव होता है। ऐसी रचनाओं में आरोह-अवरोह, वादी-संवादी आदि के हृस्व-दीर्घ तथा अलपत्व व बहुत्व का नियम अच्छी तरह पालन किया जाता है। ऐसी स्वर रचनाओं में पूर्वांग के स्वर उतरांग के स्वरों के साथ पूर्णतया सम्बन्ध रखते हैं। ऐसी स्वर रचना वाले रागों को स्वयं राग कहना चाहिए और इन स्वतंत्र रागों की छाया जिन रागों में हो उन्हें रागांग कहना चाहिए। स्वतंत्र रागों का तो मूल नाम है ही, इनसे निकलने वाले उपरागों को रागांग कहा जाएगा। ${ }^{10}$ इस आधार पर किया गया राग वर्गीकरण रागांग पद्धति के नाम से अधुना समय में प्रचार में है। पं. नारायण मोरेश्वर खरे ने 26 मुख्य रागांग बताए हैं, इन 26 रागांगों ${ }^{11}$ में उन्होने प्रचलित रागों का वर्गीकरण इस प्रकार किया है -

1. भैरव - भैरव, कलिंगड़ा, जोगिया, गुणक्री, गौरी, शिवमत, रामकली, अहीर, प्रभात, मंगल, बैरागी, शोभाकरी।

2. बिलावत - बिलावल, अल्हैया, सरपरदा, कुकुभ, लच्छा, शुक्ल, यमनी, देवगिरी, जैज, सुखिया ।

3. कल्याण - कल्याण, शुद्धकल्याण या भूपकल्याण, यमन, चन्द्रकान्त, तीव्र कल्याण, पहाड़ी, हेमकल्याण, जैत कल्याण।

4. खमाज - खमाज, झिंझोटी, तिलंग, मांड, खम्बावती।

5. काफी - काफी, सिंधोरा, आनन्द भैरवी।

6. पूर्वी - पूर्वी, पूरिया धनाश्री, परज । 
7. मारवा - मारवा, भटियार, भंखार, पूरिया ।

8. तोड़ी - तोड़ी, गुर्जरी तोड़ी, छाया तोड़ी, मुलतानी ।

9. भैरवी - भैरवी, मालकौस, भूपाली, सिंधुभैरवी।

10. आसावरी - आसावरी, जौनपुरी, गांधारी, देवगंधार, कोमल आसावरी, देसी।

11. सारंग - वृन्दावनी सारंग, मेघ, शुद्ध सारंग, मध्यमाद सारंग ।

12. धनाश्री - धनाश्री, भीमपलासी, धानी, पटदीप, प्रदीपिका, हंसध्वनि।

13. ललित - ललित, बसन्त, पंचम, प्रभात, ललितागौरी।

14. पीलू - पीलू, बरवा, बडहंस।

15. सोरठ - सोरठ, देस, तिलक कामोद, जयजयवन्ती।

16. विभास - विभास, देवा, जैतश्री।

17. नट - नट, गौड़ ।

18. श्री - श्रीराग, चैपी, दीपक।

19. बागेश्री -बागेश्री, रागेश्री, बहार, कौशिक कान्हड़ा।

20. केदार - केदार नट, भवानी केदार, कामोद, जलधर केदार ।

21. शंकरा — शंकरा, मालश्री, बिहाग, हंसवर्धन।

22. कान्हड़ा - दरबारी, अडाना, सुघराई, शहाना, नायकी, गुंजी, कान्हड़ा मल्हार, हुसैनी कन्हड़ा, मुद्रिकी, कौसी, आभोगी।

23. मल्हार - मल्हार, रामदासी मल्हार, सूरमल्हार, गौडमल्हार, मेघ मल्हार, नट मल्हार, चरजू की

24. हिंडोल - हिंडोल, सोहनी, भिन्न षड़ज, शुद्ध सोहनी।

25. भूपाली -भूपाली, देसकार, जयंत, जैत कल्या $\mathrm{T}$ ।

26. आसा - आसा, दुर्गा भवानी ।

इस प्रकार उक्त रागांओं को पं० नारायण मोरेश्वर खरे ने 26 मुख्य रागांगों में प्रचलित रागों को उनके अंग के आधार पर विभाजित किया।

श्री कृष्णधन बनर्जी ने भी अपने ग्रन्थ 'गीतसूत्रसार' में रागांग पद्धति को महत्वपूर्ण स्थान दिया हैं। आधुनिक समय में ख्याति लब्ध गायक व कलाकारों ने क्रियात्मक क्षेत्र में सराहनीय तथा रचनाकारों ने भी अपनी-अपनी कृतियों में रागांग पद्धति को पर्याप्त सम्मान प्रदान किया है। सुप्रसिद्ध गायक 
एवं शास्त्रकार पं0 ओंकारनाथ ठाकुर जी ने 'संगीताजलि' (भाग 1-6) में रागों के शास्त्रीय परिचय में उनके अंग राग का उल्लेख भी किया है। पं० विनायक पटवर्धन ने 'राग विज्ञान' के भाग-6 में पं० नारायण मोरेश्वर खरे द्वारा 'रागांग पद्धति' विषय पर लिखित लेख को प्रकाशित कराया है। इसी प्रकार पं० रामाश्रय झा जी पुस्तक 'अभिनव गीतांजलि' (भाग 1-5) में भी राग परिचय में रागांग तत्व को महत्वपूर्ण सथान प्राप्त है। उन्होंने रागों की शास्त्रीय व्याख्या में रागों में निहित अंग को विशेष रूप से बताया है। पं. बसन्त राव राजोपाध्याय ने अपनी पुस्तक 'संगीतशास्त्र' में रागांग को पर्याप्त सम्मान प्रदान किया है। इतना ही नही, वर्तमान समय में संस्थागत शिक्षा में भी संगीत विषय में रागांग पद्धति को पाठ्यक्रम के अन्तर्गत समाहित किया जा रहा है वर्तमान समय में विश्वविद्यालयी संगीत शैक्षणिक पाठ्यक्रम के अन्तर्गत भी रागांगो को समाहित किया जा रहा है। यथा काशी हिन्दू विश्वविद्यालय, राजामानसिंह तोमर संगीत विश्वविद्यालय, वनस्थली विद्यापीठ, मुम्बई विश्वविद्यालय, पंजाब विश्वविद्यालयों में रागांगों को प्राथमिकता दी जा रही है। मंचीय ख्याति लब्ध कलाकार भी अपनी प्रस्तुतियों में रागांग को विशेष स्थान दे रहे हैं, क्यूँकि राग की प्रस्तुति तो रागांग पर ही निर्भर होती है। राग विस्तार उसमें निहित अंग विशेष के आधार पर ही किया जाता है चूंकि थाट भी राग का आधार है, किन्तु रागांग तो राग का सौन्दर्य है तथा सौन्दर्य ही राग की पहचान है।

\section{रागांग पद्धति की विशेषतायें}

- राग की रंजक अनुभूति

- राग विशेष से परिचित होने के लिए रागांग सर्वोपरि तत्व

- एक स्वर के दो रूप प्रयुक्त रागों हेतु उपयोगी

- राग वर्गीकरण आसान (मुख्य रागों के अन्तर्गत समान विशेष वाले रागों का समाहित होना) यद्यपि रागांग के शाब्दिक अर्थ पर प्रकाश डालें तो राग वाचक स्वर समुदाय है। रागांग का तात्पर्य राग के उस विशेष अवयव से है और जो कि राग के उस पक्ष से जुड़ा है जिसमें स्थित निश्चित स्वर समूहों एवं उसमे निहित लय संचरण तथा सभी अलंकरण (मीड़, कण, खटका, मुर्की, आन्दोलन) से राग अपने विशिष्ट स्वर में मुखरित हो उठता है। कोई भी राग अपने विशिष्ट स्वर समूह, उसके प्रयोग क्षेत्र व प्रचार क्षेत्र के आधार पर अपने आप में रागांग राग कहला पाने में सक्षम बनता है। यूं तो प्रत्येक राग की अपनी एक विशिष्ट पहचान होती है तभी तो वह दूसरे से भिन्न जान पड़ता है किन्तु यह भी तो है कि हर ऐसे राग को रागांग भी तो नही कहा जा सकता। यद्यपि राग के कुछ विशिष्ट गुणों को मुख्य मानकर उसके समान गुणों के जैसा एक समूह लाकर एक वर्ग घोषित किया जाता है जिसे रागांग से अभिहित किया जाता है। इस आधार पर रागांग वर्गीकरण पद्धति के नाम से उत्तर भारतीय संगीत में प्रचारित है। 


\section{निष्कर्ष}

स्पष्टतः यह साथ ही प्रतीत होता है कि संगीत में रागांग के सम्यक ज्ञान के बगैर रागों के प्रकारों का अध्ययन अत्यन्त कठिनसाध्य है क्योंकि अंगो की सहायता से ही राग के विभिन्न प्रकारों का निर्माण किया जाता है। प्रत्येक मूल राग का एक निश्चित अंग होता है, वह विशिष्ट अंग उस राग परिवार के करने में आसानी होती है। तथापि अनेकानेक अंगों के अन्तर्गत वर्गीकृत किये गये असीमित रागों की प्रकृति व सौन्दर्य उस राग में निहित स्वर विशेष्य के अनुरूप अपना स्वतंत्र अस्तित्व रखने में समर्थ होती हैं।

\section{संदर्भ}

1. एस एन रातंजनकर, लक्ष्य संगीत थाट पद्धति, संगीत पत्रिका, जून 1955 पृ.-23

2. मतंग मुनिकृत वृहद्देशी श्लोक 349

3. शारंगदेव कृत संगीत रत्नाकर, रागाध्याय श्लोक-1

4. शारंगदेव कृत संगीत रत्नाकर, रागाध्याय श्लोक - 2

5. शारंगदेव कृत संगीत रत्नाकर, रागाध्याय श्लोक 10-11

6. पार्श्वदेवकृत संगीत समयसार चतुर्थ अध्याय श्लोक-1

7. उमापतिकृत औमापतम् 12वां अध्याय श्लोक 174-176।

8. नारद कृत संगीत मकरंद श्लोक 66-67।

9. संगीतोपनिषद्सारोद्धार तृतीय अध्याय श्लोक 112

10. विनायक पटवर्धन राग विज्ञान भाग-6 पृष्ठ-11

11. राग विज्ञान भाग-6 विनायक पटवर्धन पृष्ठ 12-14

सन्दर्भ ग्रन्थ

पाठक, डा. सूचना (2016) हिन्दुस्तानी संगीत में राग की उत्पत्ति एवं विकास, राधा पब्लिकेशन नई दिल्ली, द्वितीय संस्करण।

नारद (1978) संगीत मकरन्द लक्ष्मीनारायण गर्ग (सम्पादक), संगीत कार्यालय हाथरस, उत्तर प्रदेश।

मतंग मुनि (1976) बृहददेशी, सम्पादक सम्ताशिव शास्त्री, बालकृष्ण गर्ग, संगीत कार्यालय हाथरस उत्तर प्रदेश

शारंगदेव (1951-1957) संगीत रत्नाकर, सम्पादक, सुब्रम डयम् शास्त्री, अड़यार प्रकाशन।

पार्श्वदेव (1977) संगीत समयसार, श्रीकुकुद भारती प्रकाशन।

उमापति (1957) औमापत्म, सम्पादक टी चन्द्रशेखरन, गवर्नमेंट ओरिएन्टेल सिरीज मद्रास।

सुधाकलश आचार्य (1961) संगीतोपनिषत्सारोद्वार, गायकवाद ओरिएन्टल सिरीज।

बसन्त (1970) रागकोष, संगीत कार्यालय, हाथरस।

पटवर्धन, विनायक राव (1964) राग विज्ञान भाग-6, संगीत गौरव ग्रन्थमाला, पुणे।

संगीत मासिक पत्रिका (जून 1955) संगीत कार्यालय हाथरस। 